\title{
Seed dispersal and predation of fleshy-fruited plants by Japanese macaques in the cool temperate zone of northern Japan
}

\section{Tatsuya Otani}

Forestry and Forest Products Research Institute, Tohoku Research Center, Morioka, Iwate 020-0123, Japan

Japanese macaques, Macaca fuscata, play an important role in dispersing seeds of fleshy-fruited plants in the warm temperate forest of Yakushima Island, southern Japan (Yumoto et al. 1998; Otani and Shibata 2000). Various plant species with fleshy fruits are also found in the cool temperate zone of northern Japan (Nakanishi 1996). The frugivorous diet of the macaque in fall, which was recorded by direct observations of foraging behavior (e.g. Nakayama et al. 1999), implies that the macaques act as a seed disperser in the cool temperate zone even at the northern limit of their range. In order to evaluate a species' role as a seed disperser, it is necessary, initially, to examine which plant species and how many seeds they disperse successfully. There have been, however, no qualitative or quantitative studies of seed dispersal by the macaques in the northern part of their range. In this study, therefore, fecal analysis was conducted to identify seed species and abundance. The size of seeds dispersed was also examined, as seed size is an important factor influencing the seed treatment by macaques (Corlett and Lucas 1990; Otani and Shibata 2000).

\section{Materials and methods}

Fecal sampling was conducted in two areas: Kashima and the Shimokita Peninsula (Fig. 1). Kashima (37 $42^{\prime} \mathrm{N}$, $140^{\circ} 50^{\prime} \mathrm{E}, 100-580 \mathrm{~m}$ a.s.1.), located in northeastern Fukushima Prefecture, is the southernmost area occupied by Japanese macaques in the east half of northern Japan (Imaki et al. 1998). On the Shimokita Peninsula, at the northern tip of Honshu Island, samples were taken from two sites, at Wakinosawa $\left(41^{\circ} 09^{\prime} \mathrm{N}, 140^{\circ} 47^{\prime} \mathrm{E}, 50-150\right.$ $\mathrm{m}$ a.s.l.) and at Kazamaura $\left(41^{\circ} 28^{\prime} \mathrm{N}, 141^{\circ} 06^{\prime} \mathrm{E}, 10-60\right.$ $\mathrm{m}$ a.s.l.). The Shimokita Peninsula is the northernmost part of the range of the Japanese macaque (Oi et al.

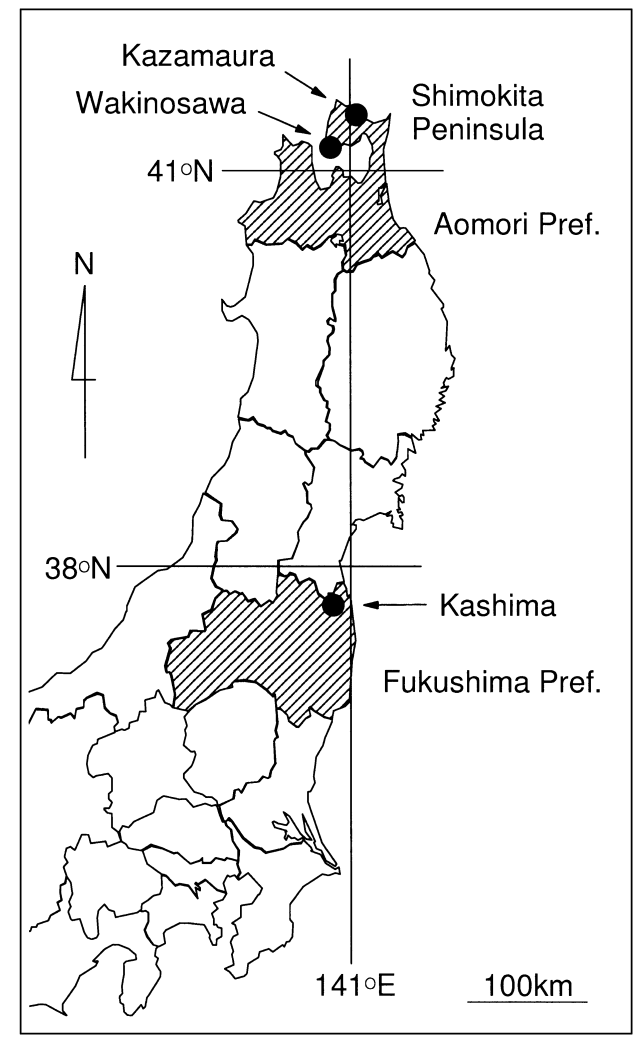

Fig. 1. Location of the Kashima and Shimokita (Wakinosawa and Kazamaura) study areas, in the cool temperate zone of northern Japan.

1997). The Kashima area is covered with a mosaic of Cryptomeria japonica plantations, logged sites, farmlands, and secondary forests dominated by Quercus serrata, Pinus densiflora, and Abies firma. The landscape of the Shimokita area is similar to that of Kashima, but the dominant species in the forests there are Fagus crenata, Quercus crispula, and Thujopsis dolabrata var. hondai. Crop raiding by the macaques has been reported from both areas (Oi et al. 1997).

Fresh feces were collected along forest roads and 
Table 1. Seeds obtained from Japanese macaque feces from Kashima and the Shimokita Peninsula, in the cool temperate zone of northern Japan.

\begin{tabular}{|c|c|c|c|c|c|}
\hline \multirow{2}{*}{ Species } & \multirow{2}{*}{ Life form } & \multirow{2}{*}{$\begin{array}{c}\text { Frequency of } \\
\text { occurrence }\end{array}$} & \multicolumn{2}{|c|}{ Mean number of seeds per feces } & \multirow{2}{*}{ Seed size $(\mathrm{mm})$} \\
\hline & & & Kashima & Shimokita & \\
\hline Actinidia arguta & vine & 0.55 & $156(57)$ & $905(43)$ & $1.6 \pm 0.1$ \\
\hline Actinidia polygama & vine & 0.28 & $992(36)$ & $1408(15)$ & $1.2 \pm 0.1$ \\
\hline Vitis coignetiae & vine & 0.19 & $27(21)$ & $20(14)$ & $3.7 \pm 0.4$ \\
\hline Akebia trifoliata & vine & 0.16 & $98(28)$ & $2(1)$ & $3.6 \pm 0.2$ \\
\hline Rubus phoenicolasius & shrub & 0.14 & $2522(15)$ & $299(10)$ & $1.2 \pm 0.1$ \\
\hline Berchemia racemosa & vine & 0.09 & $4(6)$ & $108(11)$ & $3.2 \pm 0.1$ \\
\hline Schisandra nigra & vine & 0.09 & $3(13)$ & $4(4)$ & $4.1 \pm 0.2$ \\
\hline Callicarpa japonica & shrub & 0.08 & $30(11)$ & $29(4)$ & $1.3 \pm 0.1$ \\
\hline Broussonetia kazinoki $\times$ B. papyrifera & shrub & 0.07 & $142(13)$ & $-(0)$ & $1.2 \pm 0.0$ \\
\hline Morus australis & shrub & 0.05 & $39(10)$ & $-(0)$ & $1.3 \pm 0.1$ \\
\hline Rubus palmatus var. coptophyllus & shrub & 0.05 & $470(9)$ & $-(0)$ & $1.2 \pm 0.1$ \\
\hline Antenoron filiforme ${ }^{*}$ & herb & 0.03 & $9(3)$ & $366(3)$ & - \\
\hline Stachyurus praecox & shrub & 0.03 & $8(6)$ & $-(0)$ & $1.4 \pm 0.1$ \\
\hline Acanthopanax sciadophylloides & tree & 0.03 & $85(5)$ & $-(0)$ & $3.3 \pm 0.2$ \\
\hline Benthamidia japonica & tree & 0.02 & $-(0)$ & $11(4)$ & $4.1 \pm 0.5$ \\
\hline Oryza sativa, ${ }^{* * *}$ & herb & 0.01 & $1(2)$ & $-(0)$ & - \\
\hline Ilex macropoda & tree & $<0.01$ & $174^{\mathrm{a}}(1)$ & $-(0)$ & $2.6 \pm 0.1$ \\
\hline Viburnum dilatatum & shrub & $<0.01$ & $-(0)$ & $3(1)$ & $3.2 \pm 0.2$ \\
\hline Prunus sp. & tree & $<0.01$ & $1(1)$ & $-(0)$ & - \\
\hline Swida macrophylla & tree & $<0.01$ & $1(1)$ & $-(0)$ & $3.3^{\mathrm{b}}$ \\
\hline Celastrus orbiculatus & vine & $<0.01$ & $-(0)$ & $2(1)$ & $2.7^{\mathrm{b}}$ \\
\hline
\end{tabular}

Species are arranged in decreasing order of the frequency of occurrence. Frequency of occurrence refers to the ratio of the number of fecal samples containing the seeds to the total number of samples collected. Mean number of seeds per feces was calculated on the basis of mean fecal volume $13.9 \mathrm{ml}$. Values in parentheses show the number of fecal samples containing the seeds. ${ }^{*}$ not fleshy-fruited species. ${ }^{* *}$ cultivated rice. ${ }^{\text {a }}$ number of seeds in one whole fecal sample (the volume of which was not determined). ${ }^{b}$ after Kominami et al. (2003).

around farmlands every third week from mid-July to the end of November in 2000 and 2001. The volume of a fecal sample was determined by soaking it in a measuring cylinder of water. Intact seeds were extracted from feces after being sieved through a nylon mesh $(0.526$ $\mathrm{mm})$, and were then sorted and counted according to species. The frequency of occurrence for each species was defined as the ratio of the number of fecal samples containing the seed to the total number of samples collected at both areas. Mean number of seeds per feces was calculated for each plant species on the basis of the mean volume of a fecal sample. Data from 2000 and 2001 were combined for the analysis.

Seed size was assessed for each of the fleshy-fruited plants extracted from feces. Three different diameters, lying at right angles to each other, were measured using digital calipers and the mean cubic diameter (MCD) was calculated. Thirty seeds were used for the measurement for each species, except for Benthamidia japonica $(n=$ 17). The MCD of Viburnum dilatatum was obtained from seeds collected from fruiting trees, because too few were found in fecal samples.

\section{Results and discussion}

A total of 182 fecal samples were collected in 2000 and 2001: 107 at Kashima and 75 from the Shimokita Peninsula. The volume of fecal samples averaged $13.9 \pm$ $7.3 \mathrm{ml}( \pm S D, n=163)$. Approximately $87 \%$ of feces contained seeds consisting of 21 species: 18 species in Kashima and 12 species in Shimokita (Table 1). The mean number of seed species in a fecal sample was $2.4 \pm$ $1.5( \pm S D, n=99)$ in Kashima, and $1.9 \pm 0.8(n=59)$ in Shimokita. All species for which the frequency of occurrence was higher than 0.03 were vines or shrubs, while the frequency of occurrence was relatively low for five 
tree species (Table 1). Actinidia arguta and A. polygama were found most frequently in both areas $(>0.25$, Table 1), followed by Vitis coignetiae, Akebia trifoliata (in Kashima), Rubus phoenicolasius, and Berchemia racemosa (in Shimokita). Mean numbers of seeds per fecal sample exceeded hundreds for Actinidia spp. and Rubus spp. (Table 1). The vine and shrub species mentioned above were found commonly at forest edges, roadsides, and logged areas, suggesting that the macaques in both sites foraged at such open sites. In Kashima, rice Oryza sativa seeds appeared with chaff in two fecal samples in August and October, providing limited support for the previous report of crop raiding by the Japanese macaque (Oi et al. 1997). Rice grains might be raided from crops and/or be gleaned from fields after harvest, as rice was usually reaped in September to October.

All of the five commonest species represented in fecal samples from each study area, reached peaks from August to October (see Table 1, and Fig. 2). The monthly variation of Actinidia arguta and $V$. coignetiae indicated similar patterns in both Kashima and Shimokita. Seed presence of A. polygama in feces peaked earlier in Shimokita than in Kashima. Akebia trifoliata seeds appeared frequently in Kashima during October. Rubus phoenicolasius appeared in feces over a longer period in Kashima than in Shimokita, and peaked in August, which was earlier than the other four species.

Seed size, defined as MCD, ranged from $1.2 \mathrm{~mm}$ to $4.1 \mathrm{~mm}$ with a mean of $2.4 \pm 1.1 \mathrm{~mm}( \pm S D, n=16$, Table 1). Schisandra nigra and Benthamidia japonica had the highest MCD $(4.1 \mathrm{~mm})$ of any of the species sampled. Seeds of Prunus spp. in both study areas, in particular $P$. ssiori and $P$. grayana, were approximately $5 \mathrm{~mm}$ in diameter (Nakayama et al. 2000). The maximum size of seeds studied ( $4.1 \mathrm{~mm}$ or approximately $5 \mathrm{~mm}$ ) was smaller than that swallowed and dispersed in Yakushima Island (6.35 mm, Elaeocarpus japonicus; Otani and Shibata 2000), implying that the macaque swallowed these seeds leaving some margins.

Evidence of seed predation was, however, obtained from some of the relatively large-seeded species (MCD $>3.0 \mathrm{~mm}$ ). Some cracked seeds of Akebia trifoliata and Berchemia racemosa were found with their intact seeds. Fragments of Prunus sp. seed were observed in seven fecal samples from Kashima, and seed fragments of Benthamidia japonica were also detected in five samples from Kashima and in two from Shimokita, intact seeds of these species were found in fewer feces. In contrast, no such evidence of seed predation was observed for (a)
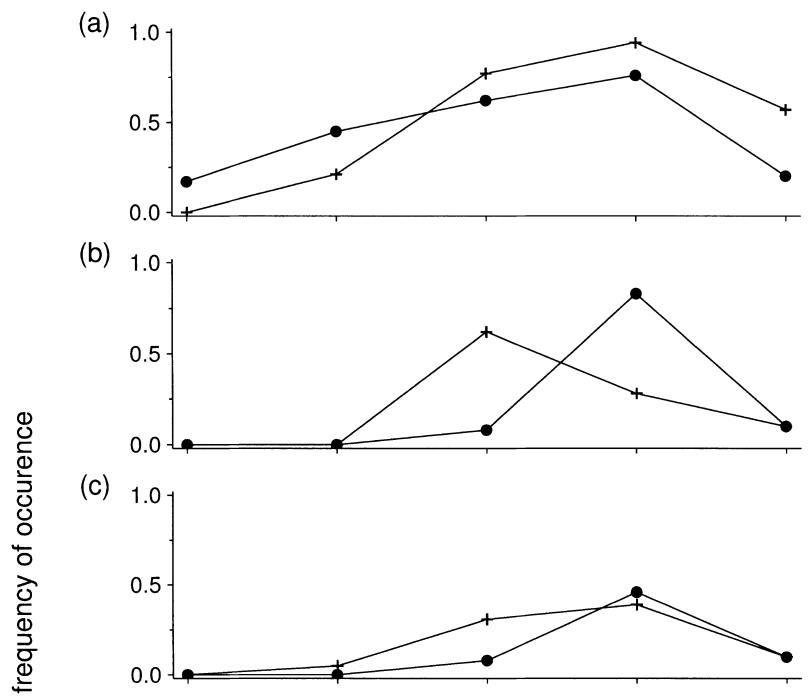

(d)

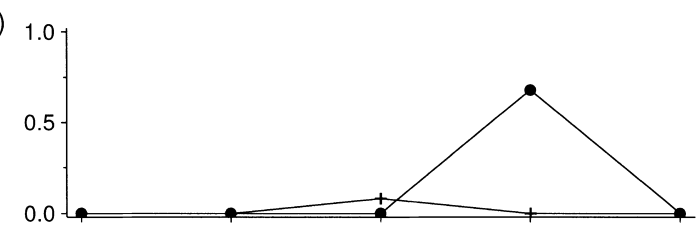

(e)

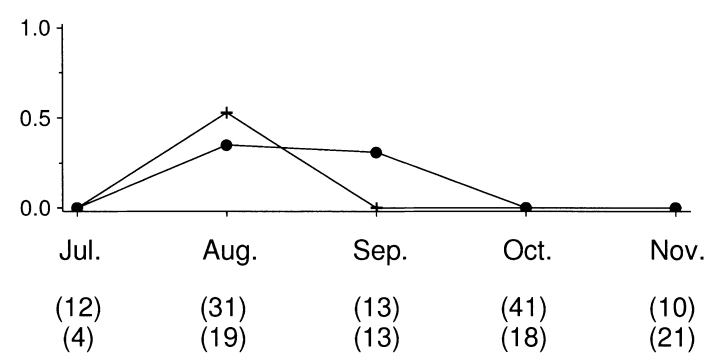

Fig. 2. Monthly frequency of seed occurrence in fecal samples collected in each area: a) Actinidia arguta, b) A. polygama, c) Vitis coignetiae, d) Akebia trifoliata, and e) Rubus phoenicolasius.

Kashima; + Shimokita. Values in parentheses show the number of all fecal samples collected in each month: upper, Kashima; lower, Shimokita.

$V$. coignetiae and $S$. nigra. These findings indicate that macaques tend to be seed predators of at least Prunus sp. and $B$. japonica, but seed dispersers of $V$. coignetiae and S. nigra.

In northern Japan, the Japanese macaque appears to contribute positively to seed dispersal of small-seeded plants, such as Actinidia spp. and $R$. phoenicolasius, whose seeds are found frequently and abundantly in feces, although the seasonal pattern of seed appearance in feces differed between study areas. Quantitative data on seed predation is still required for large-seeded plants in order to determine whether the macaques act as seed dispersers or seed predators. 
Acknowledgments: I am grateful to K. Otsuki and J. Uetsuki for the information of distribution status for the macaques, and to Y. Kominami for the identification of some seeds. I also acknowledge T. Masaki, T. Oka, and M. A. Brazil for constructive comments on the manuscript.

\section{References}

Corlett, R. T. and Lucas, P. W. 1990. Alternative seed-handling strategies in primates: seed-spitting by long-tailed macaques (Macaca fascicularis). Oecologia 82: 166-171.

Imaki, H., Izumiyama, S., Iwamaru, D., Okada, M., Okano, M., Kabaya, H., Koganezawa, M., Shirai, K. and Morimitsu, Y. 1998. Current distribution and management status of Japanese monkey (Macaca fuscata) in the Kantou-Koushinetsu district, Japan. Wildlife Forum 4: 35-52 (in Japanese).

Kominami, Y., Sato, T., Takeshita, K., Manabe, T., Endo, A. and Noma, N. 2003. Classification of bird-dispersed plants by fruiting phenology, fruit size, and growth form in a primary lucidophyllous forest: an analysis, with implications for the con- servation of fruit-bird interactions. Ornithological Science 2: $3-23$.

Nakanishi, H. 1996. Fruit color and fruit size of bird-disseminated plants in Japan. Vegetatio 123: 207-218.

Nakayama, S., Inokuchi, M. and Minamitani, T. 2000. Seeds of Wild Plants in Japan. Tohoku University Press, Sendai, 642 pp. (in Japanese).

Nakayama, Y., Matsuoka, S. and Watanuki, Y. 1999. Feeding rates and energy deficits of juvenile and adult Japanese monkeys in a cool temperate area with snow coverage. Ecological Research 14: 291-301.

Oi, T., Mori, O., Ashizawa, S., Matuoka, S., Agetuma, N., Nakamura, T., Endo, J., Iwatuki, K., Otuki, K. and Izawa, K. 1997. The distribution and the conservational status of wild Japanese macaques (Macaca fuscata fuscata) in Tohoku district, Japan. Wildlife Forum 3: 5-22 (in Japanese).

Otani, T. and Shibata, E. 2000. Seed dispersal and predation by Yakushima macaques, Macaca fuscata yakui, in a warm temperate forest of Yakushima Island, southern Japan. Ecological Research 15: 133-144.

Yumoto, T., Noma, N. and Maruhashi, T. 1998. Cheek-pouch dispersal of seeds by Japanese monkeys (Macaca fuscata yakui) on Yakushima Island, Japan. Primates 39: 325-338.

Received 24 July 2003. Accepted 26 August 2003. 